ARTIGO

\title{
O financiamento educacional no Espírito Santo: o que dizem os gestores de Educação Especial
}

\author{
Marileide Gonçalves França ${ }^{a}$ \\ Douglas Christian Ferrari de Melo ${ }^{b}$ \\ Mariangela Lima de Almeida ${ }^{c}$
}

\section{Resumo}

O artigo analisa a compreensão dos gestores de Educação Especial do estado do Espírito Santo acerca do financiamento dessa modalidade de Ensino. Assume, como perspectiva teórico-metodológica, a pesquisa-ação colaborativo-crítica, que se ocupa simultaneamente da ação e da investigação. A pesquisa evidencia que alguns gestores demonstram ter conhecimento sobre o financiamento da Educação Especial, em relação à fonte de recursos, normativas, dupla matrícula no Fundeb e programas específicos. No entanto, faz-se necessário destacar os gestores que desconhecem a temática, o que revela o desafio da formação para esses profissionais que atuam na gestão da Educação Especial nos municípios. Palavras-chave: Financiamento da Educação. Gestão Educacional. Educação Especial.

\section{Introdução}

O debate acerca do seu financiamento da Educação Especial se desenvolveu a partir do momento em que o Estado brasileiro direcionou recursos específicos, para as políticas e às ações voltadas ao atendimento das pessoas com deficiência no Brasil. Dessa forma, a Educação Especial, como política pública, constitui um processo recente na sociedade brasileira (MAZZOTTA, 2011).

O debate sobre financiamento sustenta-se na concepção de política pública, que, segundo Boneti (2003, p. 15), é a "[...] ação que nasce do contexto social, mas que

\footnotetext{
a Universidade Federal do Espírito Santo, Alegre, ES, Brasil.

b Universidade Federal do Espírito Santo, Vitória, ES, Brasil.

c Universidade Federal do Espírito Santo, Vitória, ES, Brasil. 
passa pela esfera estatal como decisão de intervenção pública numa realidade, quer ela seja econômica ou social". Como consequência, a discussão do financiamento dessa modalidade de Ensino se articula ao contexto do financiamento da Educação.

Os recursos relativos à Educação Especial no Brasil, ainda na década de 1980, eram muito reduzidos, restritos às fontes da União, por meio de programas prioritariamente destinados às instituições privadas dessa modalidade (GOMES; AMARAL SOBRINHO, 1996; KASSAR; REBELO, OLIVEIRA, 2019). Com a promulgação da Constituição Federal de 1988 (CF/88), o financiamento da Educação caracterizou-se pela descentralização financeira. O percentual de verbas vinculado à Educação atribuído à União foi elevado de $13 \%$ para $18 \%$, conforme art. 212 da CF/88, para "[...] nunca menos de dezoito, e os Estados, o Distrito Federal e Municípios vinte e cinco por cento, no mínimo, da receita resultante de impostos, compreendida a proveniente de transferências, na manutenção e desenvolvimento do Ensino" (BRASIL, 1988). A Educação Especial também foi contemplada, tendo em vista o dever do Estado em promover, de acordo com o art. 208, inciso III, o "[...] atendimento educacional especializado aos portadores de deficiência, preferencialmente na rede regular de Ensino" (BRASIL, 1988).

As políticas de Educação Especial engendraram um novo desafio aos sistemas municipais, grandes responsáveis pelas matrículas da Educação Básica após a municipalização ${ }^{1}$, pois tiveram que assumir grande parte dos alunos que estavam nas instituições privadas de Educação Especial, além daqueles que ainda não tiveram acesso a qualquer serviço educacional (KASSAR; REBELO, 2018). De acordo com Bassi (2012), ao analisar a distribuição do total de matrículas dessa modalidade por Dependência Administrativa no Brasil, a esfera municipal foi o ente federado que assumiu preponderantemente a sua oferta no país, no período de 2007 a 2012. Cumpre destacar que esse aumento de matrículas do público alvo da Educação Especial nos sistemas educacionais brasileiros é decorrente da Política Nacional de Educação Especial na Perspectiva da Educação Inclusiva - PNEE-EI/2008 (BRASIL, 2008), que passou a orientar os sistemas de Ensino para a organização de serviços e de recursos de Educação Especial. O objetivo era promover respostas às necessidades educacionais especiais dos alunos com deficiência, Transtornos Globais de Desenvolvimento (TGD) e altas habilidades/superdotação, reafirmando a Educação Especial como modalidade da Educação escolar que, portanto, perpassa todos os níveis de Ensino, desde a Educação Infantil até a Educação Superior, abrangendo também as modalidades de Ensino.

${ }^{1}$ Entende-se como municipalização "[...] a iniciativa, no âmbito do poder municipal, de expandir suas redes de Ensino, ampliando o nível de atendimento por parte desta esfera da administração pública; como o processo de transferência de rede de Ensino de um nível da administração pública para outro, geralmente do estadual para o municipal" (OLIVEIRA, 1997, p. 174). 
Tal cenário também significou novas demandas para os gestores públicos dessa modalidade no que se refere à gestão política, pedagógica e financeira das políticas e ações direcionadas ao público-alvo. Estudos que analisam esse movimento em municípios brasileiros (PRIETO; PAGNEZ; GONZALEZ, 2014; CICHELERO; LUNARDI, 2019) indicam a busca do órgão gestor municipal em assegurar que as reformas propostas sejam efetivadas em seus sistemas educacionais.

Nesse contexto, analisamos o conhecimento do gestor da Educação Especial acerca do processo de gestão do financiamento educacional, que envolve o planejamento orçamentário, as despesas e o controle social dos recursos públicos. Considera-se que sua participação nos processos decisórios sobre os recursos a serem aplicados na Educação é de extrema importância para a garantia da materialização das políticas dessa modalidade, nos diferentes sistemas municipais de Ensino.

Entendemos a gestão educacional na perspectiva democrática (FLACH, 2020), que viabiliza a participação de todos, nos processos de decisão, nas diferentes instâncias do Estado, e na formulação de políticas públicas, como afirmam Camargo e Bassi (2008, p. 97):

[...] presente em diferentes instâncias da gestão pública da Educação, desde as unidades escolares até os organismos de Estado de participação institucional (conselhos de Educação), sem os quais ou não são repassadas verbas de outras esferas federativas ou não se pode constituir um sistema de Ensino público.

No estado do Espírito Santo (ES), as pesquisas realizadas (JESUS, 2012; MELO, 2016) expõem fragilidades nas redes de Ensino para a implementação de políticas inclusivas. Um dos desafios têm sido a formação dos profissionais responsáveis pela gestão da Educação Especial, nas secretarias municipais e superintendências regionais de Educação (MELO, 2016).

Esse cenário impulsionou, a partir de 2010, diferentes iniciativas de pesquisa e extensão nas universidades, tendo como foco a formação continuada de gestores de Educação Especial. Em 2013, o movimento de colaboração com esses gestores públicos foi intensificado com a criação do grupo de estudo-reflexão "Gestão de Educação Especial”, coordenado pelo Grufopees ${ }^{2}$, constituindo-se, assim, num importante lócus de discussão das políticas de Educação Especial na perspectiva inclusiva. Mais recentemente, diante do contexto da política educacional no

\footnotetext{
${ }^{2}$ Grupo de Pesquisa "Formação, Pesquisa-Ação e Gestão de Educação Especial" - Conselho Nacional de Desenvolvimento Científico e Tecnológico/Universidade Federal do Espírito Santo (CNPq/UFES).
} 
país e no ES, o grupo toma como objeto de discussão o financiamento da Educação Especial.

Nessa direção, iniciamos, em 2018, a pesquisa "Políticas, Gestão e Financiamento da Educação Especial: processos formativos com gestores municipais do Espírito Santo", com o objetivo de analisar a política, a gestão e o financiamento da Educação Especial nos municípios do estado do Espírito Santo, pela via da pesquisa-ação colaborativo-crítica. Temos como foco a formação dos gestores para o acesso e a permanência dos alunos público-alvo da Educação Especial (PAEE), nas escolas comuns da Educação Básica.

Desse modo, objetiva-se, nesse texto, analisar a compreensão dos gestores dessa modalidade, no estado do Espírito Santo, acerca do financiamento a ela destinado. Para isso, o artigo organiza-se em quatro seções: inicialmente apresentamos a perspectiva teórico-metodológica do estudo, focalizando o contexto, os participantes e os procedimentos de produção e de análise dos dados; posteriormente, discutimos o financiamento da Educação Especial no Brasil e no Espírito Santo. Num terceiro momento, dialogamos com os gestores acerca de suas concepções o financiamento dessa área. Por fim, trazemos algumas reflexões a partir desse processo de mapeamento das políticas que nos impulsiona novos/outros processos de pesquisa e extensão.

\section{O contexto e a perspectiva teórico-metodológica do estudo}

Esse estudo assume como perspectiva teórico-metodológica a pesquisa-ação colaborativo-crítica que, conforme Carr e Kemmis (1988), constitui-se como investigação emancipatória, vinculando teorização educacional e prática à crítica, em um processo que se ocupa simultaneamente da ação e da investigação. Nesse sentido, a pesquisa-ação interroga a relação hierarquizada entre acadêmicos e atores do contexto, propondo, assim, um processo de produção de conhecimento com o outro e não para o outro. Torna-se essencial, portanto, uma constante escuta sensível (BARBIER, 2004) das demandas advindas do contexto vivido pelos gestores.

Movidos por essa premissa, realizamos um mapeamento das políticas de Educação Especial em municípios capixabas, tomando como princípio a necessidade de ampliar a escuta e as trocas intersubjetivas com os sujeitos do contexto educativo. Nesse texto, abordamos o primeiro momento da pesquisa, no qual buscamos analisar as concepções e os movimentos instituídos pela gestão de Educação 
Especial nas redes municipais de Ensino do ES por meio de um questionário semiestruturado, enviado eletronicamente (Formulário Google). O questionário foi enviado para as 78 redes municipais de Ensino capixaba, nos quais tivemos retorno de 48 municípios, o que representa $61,53 \%$ das respostas dos gestores.

Com vistas a compreender as demandas e as concepções dos gestores de Educação Especial acerca do financiamento dessa modalidade de Ensino, a análise dos dados organizou-se em dois momentos. Inicialmente, organizamos categorias temáticas considerando a análise de conteúdo referidas por Bardin (2004). Posteriormente, estabelecemos um diálogo entre autores da literatura científica e autores do contexto - gestores. Assumimos como premissa que, no lugar do sujeito solitário, na reflexão que toma a si mesmo por objeto, entra a ideia de um conhecimento mediatizado e relacionado com o agir, por meio da vinculação da prática e da comunicação cotidianas, assumindo o caráter intersubjetivo e cooperativo (HABERMAS, 2003) na produção de conhecimentos.

\section{O financiamento da Educação Especial no Brasil e no Espírito Santo}

A CF/88, ao estabelecer a vinculação de recursos para a manutenção e o desenvolvimento do Ensino, também contemplou a Educação Especial, tendo em vista o dever do Estado em garantir o AEE às pessoas com deficiência na rede regular de Ensino. Cabe ressaltar, no âmbito dessa Constituição, no art. 213, a possibilidade de repasse de recursos do financiamento da Educação pública às instituições privadas para complementar os atendimentos ao público dessa modalidade.

A década de 1990 iniciou-se, de acordo com Arelaro (2000), com movimentos contraditórios marcados, por um lado, pelo processo constituinte, que gerou a $\mathrm{CF} / 88$, e pelo desejo de implementação dos direitos sociais nela introduzidos e, por outro, com um projeto neoliberal, baseado na redução do papel do Estado e do financiamento voltado às políticas sociais, atendendo à lógica de mercado. $\mathrm{Na}$ Educação, esse período foi marcado por mudanças nas políticas educacionais, como a aprovação da Lei de Diretrizes e Bases da Educação Nacional (LDB/1996) e na organização do financiamento da Educação, com a implantação de fundos específicos voltados à manutenção e ao desenvolvimento do Ensino.

O Fundo de Manutenção e Desenvolvimento do Ensino Fundamental e de Valorização do Magistério (Fundef) foi instituído pela Emenda Constitucional $n^{o}$ 14/96 (BRASIL, 1996a), e regulamentado pela Lei no 9.424/96 (BRASIL, 
1996b), como fundo de natureza contábil em cada unidade da federação, tendo vigorado até o ano de 2006. O Fundef, no âmbito da política de fundos, redistribui equitativamente, por meio de parâmetros de valor aluno, parte substancial da receita da vinculação de estados e de municípios, conforme a sua responsabilidade para o atendimento ao Ensino Fundamental.

No que se refere à Educação Especial, a legislação do Fundef prescreveu a definição de um valor mínimo por aluno-ano, diferenciado do valor mínimo nacional, de acordo com o nível de Ensino e o tipo de estabelecimento, que considerasse os valores por aluno (BRASIL, 1996b). Vale ressaltar que, até 1999, não houve nenhum tipo de diferenciação de valores nos custos do Fundef em relação aos estabelecidos para todas as etapas e modalidades de Ensino. Entre 2000 e 2004, estipulou-se um acréscimo de $5 \%$ do valor aluno, para alunos de $5^{\mathrm{a}}$ a $8^{\mathrm{a}}$ séries e da Educação Especial, superior ao definido para o das séries iniciais urbanas do Ensino Fundamental. Em 2003, “[...] o governo federal vetou projeto aprovado pelo Congresso que incluía as instituições filantrópicas de Educação Especial nos recursos do Fundef e atendia a reivindicação das instituições: serem consideradas entidades públicas de Educação Especial” (FERREIRA, 2009, p. 62).

No ano de 2007, houve a implantação do Fundo de Manutenção e Desenvolvimento da Educação Básica (Fundeb), criado pela Emenda Constitucional n ${ }^{\circ}$ 53/2006, e regulamentado pela Lei $n^{\circ} 11.494 / 2007$ (BRASIL, 2007a), e pelo Decreto $\mathrm{n}^{\mathrm{o}}$ 6.253/2007 (BRASIL, 2007b), em substituição ao Fundef. O período de vigência estabelecido para o Fundeb foi de 2007 a 2020.

O Fundeb garantiu que os recursos vinculados à Educação fossem aplicados na Educação Básica, por meio de seu mecanismo de distribuição de recursos com base no número de alunos das diversas etapas e modalidades, informado no Censo Escolar do ano anterior, sendo computados os estudantes matriculados nos respectivos âmbitos de atuação prioritária, conforme o art. 211 da CF/88 (BRASIL, 1988). Na versão final do Fundeb, foram acrescentadas as matrículas de Educação Infantil e da Educação Especial da rede conveniada sem fins lucrativos. Segundo Pinto (2007, p. 888), essa inclusão representou “[...] um duro golpe no princípio de que recursos públicos devem se destinar às instituições públicas", mas foi resultante da constatação de que muitos municípios brasileiros mantinham convênios com instituições sem fins lucrativos e sua exclusão significaria deixar milhares de crianças sem atendimento.

A distribuição de recursos no Fundeb também considerou os fatores de ponderação, definidos anualmente pela Comissão Intergovernamental de Financiamento para 
a Educação Básica de Qualidade. Conforme Viegas e Bassi (2009), as etapas e as modalidades são consideradas com pesos diferenciados na distribuição de recursos, no novo desenho do financiamento da Educação, situados em uma escala entre 0,7 a 1,3 pontos $^{3}$. A posição de cada especificidade nessa escala toma como referência o fator de ponderação de valor 1,0, definido para a matrícula das séries iniciais urbanas do Ensino Fundamental. O valor mínimo por aluno-ano da Educação Especial passou a receber um peso ponderado 20\% superior ao valor por aluno de referência.

O Decreto $\mathrm{n}^{\circ}$ 7.611/2011 (BRASIL, 2011) também acrescenta dispositivo ao Decreto $\mathrm{n}^{\circ}$ 6.253/2007 (BRASIL, 2007b). A partir desse decreto, os alunos PAEE passaram a ser contabilizados duplamente no âmbito do Fundeb. Essa dupla contabilização refere-se ao valor aluno relacionado à matrícula na classe comum do Ensino regular e no AEE, que pode ser realizado na mesma escola que o aluno frequenta, em outra do seu entorno ou em instituições comunitárias, confessionais ou filantrópicas sem fins lucrativos, que prestem esse tipo de serviço.

No PNE (2014-2024), a Educação Especial foi contemplada na Meta 4:

Universalizar, para a população de 4 (quatro) a 17 (dezessete) anos com deficiência, transtornos globais do desenvolvimento e altas habilidades ou superdotação, o acesso à Educação Básica e ao atendimento educacional especializado, preferencialmente na rede regular de Ensino, com a garantia de sistema educacional inclusivo, de salas de recursos multifuncionais, classes, escolas ou serviços especializados, públicos ou conveniados (BRASIL, 2014).

Para alcançar essa meta, o PNE estabeleceu 19 estratégias para a Educação Especial que, entre outras, abrangem o financiamento dessa modalidade. O processo de tramitação e aprovação do PNE, mais uma vez, apresentou as correlações de forças existentes historicamente, na definição de políticas da Educação Especial, marcadas pelas disputas entre os grupos das entidades privadas, as organizações do setor público e o governo, para a oferta do atendimento educacional e para a obtenção dos recursos públicos destinados à Educação Especial. Ficou evidente a forte capacidade das entidades privadas de influenciar os parlamentares na garantia da manutenção do AEE pelas instituições comunitárias, confessionais ou filantrópicas sem fins lucrativos por meio de convênios com o poder público. ${ }^{3}$ Os valores de ponderação utilizados na escala pelos autores são definidos pela Comissão Intergovernamental
de Financiamento para a Educação Básica de Qualidade. 
Analisando a realidade de um município da Grande Vitória/ES, França (2014) apontou que a política do Fundeb garantiu mais recursos para a Educação Especial, principalmente a partir do estabelecimento de um fator de ponderação diferenciado para essa modalidade e do Decreto $\mathrm{n}^{\circ} 7.611 / 2011$, que estipulou a dupla matrícula. No entanto, destaca que, no âmbito do Fundo, não há regulamentação que assegure a alocação e a aplicação de recursos exclusivos nessa modalidade de Ensino. Desse modo, as verbas contabilizadas, a partir do cômputo das matrículas dos estudantes PAEE, podem ter sido dirigidas a outras etapas e modalidades.

No Espírito Santo, a política de Educação Especial passou por três períodos diferentes em duas décadas. No primeiro momento, de 2008 a 2013, o estado tentou implementar suas ações, seguindo, em linhas gerais, as diretrizes nacionais. No segundo período, de 2014 a 2016, houve a promulgação da Portaria $\mathrm{n}^{\circ}$ 92-R/14 (ESPÍRITO SANTO, 2014), que previu, a partir de um edital de credenciamento, mudanças na forma de financiamento do AEE, possibilitando, na prática, a "terceira matrícula"4. O terceiro momento estendeu-se de 2017 a 2018, marcado por um "termo de cooperação técnica" entre o governo do estado e os municípios, transferindo o AEE das escolas públicas para as instituições privadas de Educação Especial, incluindo os recursos oriundos da segunda matrícula do Fundeb.

Nesse sentido, Oliveira (2016) evidenciou o aumento do número de matrículas nas instituições privadas de Educação Especial no ES, com maior expressão a partir do ano de 2014, após a mudança da relação do estado com essas instituições, permitida por meio de convênio para contrato de serviços de AEE, o que culminou também no aumento de recursos públicos a elas destinados. Além disso, mostrou, por um lado, que a compra dos serviços de AEE pelo governo do ES (terceirização) proporcionou aumento nos repasses de recursos públicos às instituições especializadas sem fins lucrativos; por outro, os recursos investidos na escola pública estadual foram menores.

Conforme apresentado, é possível observar que o governo do estado tem assumido posições contraditórias nas políticas educacionais. Ao mesmo tempo que preconiza $\mathrm{o}$ atendimento nas escolas municipais, abre a possibilidade para as parcerias entre organizações governamentais e não governamentais.

\footnotetext{
${ }^{4} \mathrm{~A}$ "terceira matrícula" refere-se a uma espécie de valor-aluno-mês de $R \$ 325,77$ oferecido aos alunos que frequentarem essas instituições. Dessa forma, o estudante recebe o duplo cômputo do Fundeb, por estar matriculado tanto na sala comum do Ensino regular quanto no AEE em turno inverso, além da terceira matrícula, se ele também for apoiado pela instituição especializada em dias diferentes (e em turno inverso) do apoio que é recebido em alguma unidade das escolas públicas.
} 


\section{As concepções dos gestores de Educação Especial sobre o financiamento educacional}

$\mathrm{Na}$ análise dos questionários de mapeamento das concepções e políticas implementadas pelos gestores de Educação Especial no ES, tivemos retorno de 48 municípios, o que representa uma amostragem de $61,53 \%$ das respostas dos gestores. Assim, para cada região do estado, tivemos mais de 50\% dos municípios que deram devolutiva.

O questionário era composto por 12 questões que abordavam temáticas sobre política, formação de professores, gestão e financiamento da Educação Especial. Nesse texto, analisaremos as respostas dos gestores quanto ao financiamento. Desse modo, objetivamos analisar a compreensão dos gestores da Educação Especial acerca do financiamento dessa modalidade nos municípios do estado do Espírito Santo. Organizamos os dados em três eixos temáticos para a discussão, conforme Gráfico 1.

Gráfico 1 - Compreensão dos gestores acerca do financiamento da Educação Especial

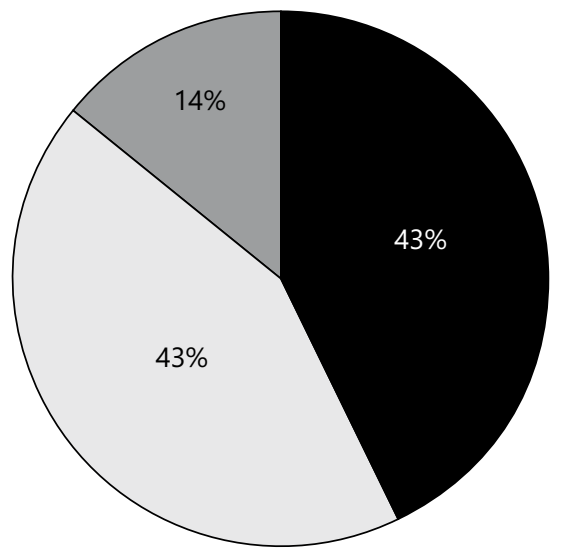

- Aqueles que informaram conhecer o financiamento no munícipio

$\square$ Aqueles que informaram não conhecer o financiamento no munícipio

$\square$ Não informaram

Fonte: Elaboração dos autores (2020). 
Como observamos, 24 gestores afirmaram ter conhecimento sobre o financiamento da Educação Especial, 24 informaram não ter conhecimento ou informação e 8 não responderam essa questão.

\section{a) Conhecimento sobre o financiamento da Educação Especial}

O trabalho do gestor da Educação Especial abrange aspectos administrativos, pedagógicos e financeiros no processo de implementação das políticas que asseguram direitos ao PAEE. De acordo com a PNEE-EI (BRASIL, 2008), os gestores devem ter conhecimentos relacionados à gestão educacional, inclusive da área de financiamento. Nesse contexto, 24 gestores afirmaram ter conhecimentos sobre os recursos voltados a essa modalidade de Ensino. Desse modo, apontaram que os municípios investiam recursos próprios na Educação Especial, por meio de programas específicos dessa modalidade de Ensino.

O município instituiu financiamento com recursos próprios - o Programa Específico de financiamento da Educação Especial no Plano Plurianual (PPA). O programa denominado Desenvolvimento e Apoio da Educação Especial com valores propostos por ano 9 milhões de reais para todas as despesas desta modalidade (transporte escolar, alimentação escolar, folha de pagamento de funcionário, passe funcionário, ticket alimentação funcionário, manutenção de equipamento e móveis, formação etc.) (MUNICÍPIO A).

No período de janeiro até agosto de 2018, o total destinado no Programa "Manutenção das atividades da Educação Especial" foi de R \$ 57. 366,54, para o pagamento dos salários dos profissionais, auxílio alimentação. De acordo com o Secretário Municipal de Finanças (MUNICÍPIO B).

Nesse contexto, evidencia-se que a Educação Especial foi contemplada no planejamento da administração municipal, o que demonstra a intenção política do município quanto a essa modalidade, considerando, como Salvador (2012, p. 5), que "[...] o orçamento público é o que garante concretude à ação planejada do Estado e espelha as prioridades das políticas públicas que serão priorizadas pelo governo". Assim, o planejamento havia previsto uma verba específica para o desenvolvimento das ações da Educação Especial.

Outros gestores disseram conhecer o financiamento da Educação Especial, a partir das atividades desenvolvidas e serviços ofertados aos alunos dessa modalidade nos municípios: 
O município investe na Educação Especial com a contratação permanente de professores e demais profissionais para atender a demanda de estudantes público da modalidade. Além disso, tem investido em melhorias na estrutura física das unidades escolares, promovendo acessibilidade nos espaços públicos. [...] Destacamos também a garantia do processo formativo que é oportunizado aos profissionais dentro e fora do horário de trabalho (MUNICÍPIO C).

Sim. O município oferta professores para atendimento educacional especializado nas salas de recursos multifuncionais, contratação de estagiários para os alunos com maiores limitações, transporte escolar acessível com cuidador, acessibilidade nas escolas (MUNICÍPIO D).

Sim. O município investe na contratação de professores para sala de recursos, profissionais para acompanharem alunos com necessidades especiais (autistas e cadeirantes) (MUNICÍPIO E).

Desse modo, os gestores destacaram ações que envolviam recursos financeiros como formação continuada de professores, contratação de diferentes profissionais de apoio, estrutura física da escola, entre outros, contudo não há indicativos que esses gestores possuam conhecimentos relativos ao financiamento da Educação, ao planejamento orçamentário, às fontes de recursos, à alocação de recursos e ao seu gerenciamento.

Alguns deles apresentaram informações mais específicas sobre a área do financiamento da Educação Especial, no que tange à fonte de receitas para as despesas vinculadas à modalidade.

O financiamento se dá através do lançamento dos alunos público-alvo da Educação Especial no Censo Escolar (tanto os que frequentam o Ensino regular, quanto os do AEE), que são computados duplamente e chegam ao município através dos recursos do Fundeb (MUNICÍPIO F).

Tenho conhecimento da duplicidade da matrícula para os alunos público-alvo da Educação Especial que fazem o AEE, porém desconheço maiores detalhes (MUNICÍPIO 6).

Sim, o financiamento se dá através do PDDE Acessível e Fundeb (MUNICÍPIO H).

Fundeb e Recurso próprio (MUNICÍPIO I). 
Os administradores demonstraram saber que os recursos são oriundos do Fundeb, que constitui um fundo especial, de natureza contábil, no âmbito estadual, e sua formação resulta da aplicação de percentuais, vinculados à receita arrecadada de impostos do Distrito Federal, dos estados e dos municípios. Revelaram ainda conhecer a legislação do Fundeb referente à dupla contabilização para os alunos com deficiência, TGD e altas habilidades/superdotação matriculados na rede regular de Ensino com AEE. Além disso, destacaram a existência de programas específicos da Educação Especial, bem como a possibilidade de os municípios investirem recursos próprios nessa modalidade.

Alguns gestores informaram, ainda, que o financiamento da Educação Especial não era exclusivo da rede de Ensino municipal, pois o município destinava recursos também às instituições privadas de Educação Especial, por meios de convênios e/ou parcerias.

Não é exclusivo do nosso município, temos parceria com a APAE [Associação de Pais e Amigos dos Excepcionais] - Bom Jesus do Itabapoana - RJ que atende nossos alunos na questão ambulatórios e CAEE (MUNICÍPIO J).

Nossa relação com a APAE é excelente, ajudamos no transporte fornecendo combustível, fornecemos merenda escolar, materiais de consumo além de um repasse realizado pela Ação Social (MUNICÍPIO K).

No Brasil, segundo Kassar, Rebelo e Oliveira (2019), o poder público, historicamente, destina financiamento público às instituições não governamentais e filantrópicas que ofertam serviços da Educação Especial, por meio de convênios ou de parcerias com as secretarias estaduais e municipais de Educação. Essa relação tende a se fortalecer no contexto de distanciamento do Estado com relação às políticas públicas. Assim, as mudanças nas relações que fundamentam o capitalismo e suas configurações nos séculos XX e XXI, a partir da redefinição do papel do Estado na execução e no financiamento das políticas sociais, se materializam na divisão de responsabilidades entre o Estado e a sociedade civil no provimento de serviços públicos à população. No caso da Educação Especial, essa parceria se (re) estrutura na vinculação do Estado com a sociedade civil organizada, constituída por organizações não estatais que ofertam atendimento educacional ao PAEE, por meio do repasse de recursos públicos a essas instituições (KASSAR; REBELO; OLIVEIRA, 2019). 


\section{b) Não conhecimento do financiamento da Educação Especial}

A gestão das políticas de Educação Especial pressupõe conhecimentos relativos ao financiamento da Educação por parte dos gestores, contudo, esse debate ainda se mostra incipiente nos processos formativos e distantes das práticas desenvolvidas por eles. De acordo com o levantamento realizado, 24 gestores responderam que não sabiam como ocorria o financiamento dessa modalidade no seu município.

\section{Não sei (MUNICÍPIO L).}

Não tenho acesso a essa informação (MUNICÍPIO M).

O setor não dispõe nesse momento dessas informações (MUNICÍPIO N).

Não sabemos valores específicos (MUNICÍPIO O).

Cabe destacar que 16 gestores responderam "Não" ou "Não sei", revelando o desconhecimento no que diz respeito aos recursos destinados à Educação Especial. Esse resultado engendra preocupação, considerando que tais profissionais são responsáveis pelo desenvolvimento de políticas, ações e organização dos serviços ofertados ao PAEE. Nesse sentido, concordamos com França e com Prieto (2018, p. 281), quando afirmam que "[...] conhecer os gastos com essa modalidade é de extrema importância para subsidiar o planejamento e a avaliação, inerentes ao processo de gestão das políticas públicas".

Outros gestores relataram que as informações referentes a receitas e a despesas da Educação Especial não pertenciam a esse setor no seu município. Desse modo, a gestão dos recursos dessa modalidade de Ensino estava sob a responsabilidade de outros setores da prefeitura.

Essa informação é diretamente com o setor financeiro (MUNICÍPIOP).

Não, o financiamento da Educação Especial é de controle da Prefeitura (MUNICÍPIO Q).

Não temos essa informação. Pertence ao setor de planejamento (MUNICÍPIO R).

Tal cenário também é corroborado por França (2014, p. 186) quando, no processo de busca de dados sobre o quantitativo de recursos destinados à Educação Especial no município de Vitória, identificou que a gestora da modalidade “[...] desconhecia como se dava esse processo, na medida em que esses dados não 
ficavam sob sua responsabilidade, tampouco ela participava da definição do planejamento orçamentário".

Essa realidade também foi encontrada em pesquisa anterior, coordenada por Jesus (2012), sobre as instituições especializadas e sobre a formação de gestores no Espírito Santo. Naquele estudo, apontaram-se as fragilidades apresentadas pelos sistemas e pelos profissionais responsáveis pela gestão da Educação Especial nos municípios do Espírito Santo. Os conhecimentos sobre gestão e implementação das políticas estão entre os maiores desafios, segundo Nogueira, Jesus e Effgen (2012, p. 165):

Gestão: falta de apoio do Poder Público; pouca clareza sobre as políticas públicas voltadas para a Educação Especial; entraves na definição de uma lei orgânica/municipal; dúvidas sobre financiamentos direcionados para a Educação Especial; dificuldade na interpretação dos aspectos legais; centralização das informações financeiras com o gestor da educação.

Outro gestor afirmou que o município não fazia diferenciação nos recursos aplicados para essa modalidade de Ensino.

O município não distingue o investimento e gasto com a Educação Especial (MUNICÍPIO S).

França (2014) e Viegas (2014) também evidenciaram essa situação em seus estudos, tendo em vista que os dados das despesas com essa modalidade estavam agregados às das outras etapas de Ensino, contribuindo para sua invisibilidade nas prestações de contas dos municípios. De acordo com Bassi e Camargo (2010, p. 300),

[...] de forma geral, as gestões municipais permanecem como zonas obscuras e resistentes a sua publicização em função de uma "tradicional forma de gestão", devido a procedimentos de reiteração burocrática da máquina pública; pode-se pensar adicionalmente que a condição de ser opaca permite à administração que os interesses estratégicos (econômicos e políticos) locais se realizem no âmbito do Estado.

Tal modelo de prestação de contas ainda engendra obstáculos tanto para a gestão da Educação Especial, no âmbito da União, dos estados e dos municípios, pois 
torna ainda mais complexo o planejamento e as políticas públicas voltadas à garantia dos direitos à Educação do PAEE, quanto para os pesquisadores (GONZALEZ; PRIETO, 2012; VIEIRA, 2014) que desenvolvem estudos referentes ao financiamento da Educação Especial e de outras modalidades de Ensino.

Alguns gestores informaram que estavam na busca de conhecer esses dados de financiamento.

Estamos buscando essas informações. O que sabemos é que o município possui um acordo com a Sedu [Secretaria de Estado da Educação] de repasse de valores para complementação do transporte escolar (MUNICÍPIO T).

Eu ainda não consegui todas essas informações (MUNICÍPIO U).

Podemos evidenciar o esforço de alguns para conhecer o financiamento da Educação Especial, que não é um processo fácil, como nos apontam França e Prieto (2018, p. 292), pois esse "[...] percurso abrange a dificuldade de acesso aos dados, a compreensão da linguagem contábil e a sua complexa forma de registro, bem como os procedimentos vinculados à publicização de informações acerca das verbas públicas destinadas à Educação", no âmbito dos municípios.

\section{Os debates sobre financiamento da Educação Especial no ES: novos/outros movimentos}

No Espírito Santo, os processos de pesquisa e de formação constituídos por meio da pesquisa-formação evidenciaram que o financiamento da Educação Especial passou a ocupar lugar importante na gestão municipal na última década. No início dos anos 2000, essa temática apresentava-se incipiente no cenário de implementação das políticas dessa modalidade nas redes de Ensino, em que a Resolução Conselho Nacional de Educação/Câmara de Educação Básica $(\mathrm{CNE} / \mathrm{CEB}) \mathrm{n}^{\circ}$ 02, de 11 de setembro 2001, que institui Diretrizes Nacionais para a Educação Especial na Educação Básica ressaltava a necessidade de criação de um setor responsável pela modalidade, que orientasse as escolas nesse processo de inclusão escolar (BRASIL, 2001). Em 2008, a PNEE-EI (BRASIL, 2008) reiterou a escolarização dos alunos PAEE na escola pública, enfatizando a organização e a implementação do AEE. Esse contexto passou a exigir das redes de Ensino novas ações da gestão da Educação Especial, que envolvem a construção de políticas efetivas para inclusão dos alunos PAEE nas escolas e conhecimentos sobre a gestão financeira dos recursos direcionados a essa modalidade de Ensino nos contextos de seus municípios. 
Nos últimos anos, o panorama político-educacional no país, com a proposta de alteração da política de Educação Especial e a instituição da tripla matrícula nas redes de Ensino do ES, motivou um amplo debate entre os gestores sobre o financiamento dessa modalidade de Ensino. Esse movimento nos conduziu a aprofundar o conhecimento sobre o financiamento da Educação Especial por meio do diálogo com os gestores das redes municipais de Ensino do Espírito Santo. Buscamos compreender, por meio da escuta sensível, as concepções que esses profissionais têm acerca do tema, considerando que os gestores são responsáveis pela articulação, construção e materialização de políticas públicas de Educação Especial nos municípios.

A pesquisa evidencia que os gestores, a partir de suas falas, demonstraram ter conhecimento de que os recursos da modalidade são oriundos do Fundeb; revelaram conhecer a legislação do Fundeb referente à dupla contabilização para os alunos da Educação Especial matriculados na rede regular de Ensino, com AEE. Além disso, destacaram a existência de programas específicos destinados à área, bem como a possibilidade de os municípios investirem recursos próprios nessa modalidade de Ensino.

Assim, embora o debate acerca do financiamento da Educação Especial seja recente, considerando que são exíguas as produções que se voltam ao estudo sobre as formas de financiamento público adotadas para garantir $\mathrm{o}$ atendimento especializado (FRANÇA; PRIETO, 2018), as informações dos gestores nos apontaram que eles estão no processo de apropriação de saberes vinculados a essa área de conhecimento. Esses resultados demonstraram a trajetória de participação desses sujeitos nos momentos formativos na universidade e/ou nos movimentos instituintes dos fóruns. No entanto, o desconhecimento referente ao financiamento da Educação Especial demonstra o desafio da formação para esses profissionais para além do aspecto pedagógico.

Nesse contexto, a escuta que buscamos evidenciar nesse artigo, por meio do mapeamento das concepções dos gestores e do panorama da política de Educação Especial, propiciou a construção de um curso de extensão de Política, Gestão e Financiamento da Educação Especial por meio de uma rede de colaboração constituída entre universidade, redes de Ensino e do Fórum de Gestores de Educação Especial do ES. O curso sustenta-se na perspectiva epistemológica e metodológica dos grupos de estudo-reflexão e objetiva colaborar com o processo formativo dos gestores municipais e estaduais dessa modalidade pela via da pesquisa-ação colaborativo-crítica e da autorreflexão organizada, tendo como foco o acesso e a permanência dos alunos PAEE nas escolas comuns da 
Educação Básica. Participam do curso 92 profissionais das redes municipais de Ensino, sendo coordenadores e técnicos de setores das secretarias de Educação; professores; diretores escolares e secretários de Educação. Assim, esse processo de mapeamento das políticas nos impulsiona a novos/outros processos de pesquisa e de extensão. 


\title{
Educational financing in Espírito Santo: what Special Education managers say
}

\begin{abstract}
The article analyzes the understanding of Special Education managers in the state of Espirito Santo regarding the financing of this type of Education. It assumes, as a theoretical-methodological perspective, the collaborative-critical action research, which is simultaneously concerned with action and investigation. The research shows that some managers demonstrate to have knowledge about the financing of Special Education, in relation to the source of resources, regulations, double enrollment in Fundeb and specific programs. However, it is necessary to highlight the managers who are unaware of the theme, which reveals the challenge of training for these professionals who work in the management of Special Education in the municipalities.
\end{abstract}

Keywords: Educational Financing. Educational Management. Special Education.

\section{Financiamiento educativo en Espírito Santo: lo que dicen los responsables de la Educación Especial}

\section{Resumen}

El artículo analiza la comprensión de los administradores de Educación Especial en el estado de Espírito Santo sobre el financiamiento de este tipo de Educación. Asume, como perspectiva teórico-metodológica, la investigación-acción colaborativa-crítica, que se ocupa simultáneamente de la acción y la investigación. La investigación muestra que algunos responsables demuestran conocimiento sobre el financiamiento de la Educación Especial, en relación a la fuente de recursos, normatividad, doble matrícula en Fundeb y programas especificos. Sin embargo, es necesario destacar a los gestores que desconocen el tema, lo que revela el desafio de la formación de estos profesionales que laboran en la gestión de la Educación Especial en los municipios.

Palabras clave: Financiamiento de la Educación. Gestión Educativa. Educación Especial. 


\section{Referências}

ARELARO, L. R. G. Resistência e submissão: a reforma educacional na década de 1990. In: KRAWCZYK, N.; CAMPOS, M. M.; HADDAD, S. (org.). O cenário educacional latino-americano no limiar do século XXI: reformas em debate. Campinas: Autores Associados, 2000. p. 95-116.

BARBIER, R. A pesquisa-ação. Brasília, DF: Líber Livro, 2004.

BARDIN, L. Análise de conteúdo. Lisboa: Edições 70, 2004.

BASSI, M. E. Financiamento da educação especial: inclusão em Santa Catarina. Poiésis, Tubarão, v. 6, n. 10, p. 377-394, jul./dez. 2012.

BASSI, M. E.; CAMARGO, R. B. Estilos de gestão da educação municipal: implicações para a gestão democrática e controle social. Revista Brasileira de Política e Administração da Educação, Porto Alegre, v. 26, n. 2, p. 209-408, maio/ago. 2010. https://doi.org/10.21573/vol26n22010.19718

BONETI, L. Educação, exclusão e cidadania. Ijuí: Unijuí, 2003.

BRASIL. Decreto ${ }^{\circ} 6.253$, de 13 de novembro de 2007. Dispõe sobre o Fundo de Manutenção e Desenvolvimento da Educação Básica e de Valorização dos Profissionais da Educação - FUNDEB, regulamenta a Lei $\mathrm{n}^{\circ} .11 .494$, de 20 de junho de 2007, e dá outras providências. Diário Oficial da União, Brasília, DF, 14 nov. 2007b.

BRASIL. Decreto n ${ }^{\circ} .7 .611$, de 17 de novembro de 2011. Dispõe sobre a educação especial, o atendimento educacional especializado e dá outras providências. Brasília, 2011a. Diário Oficial da União, Brasília, DF, 18 nov. 2011.

BRASIL. Emenda Constitucional n ${ }^{\circ}$ 14, de 12 de setembro de 1996. Modifica os arts. 34, 208, 211 e 212 da Constituição Federal e dá nova redação ao art. 60 do Ato das Disposições Constitucionais transitórias. Diário Oficial da União, Brasília, DF, 13 set.1996a.

BRASIL. Emenda Constitucional no 53, de 19 de dezembro de 2006. Dá nova redação aos arts. 7, 23, 30, 206, 208, 211 e 212 da Constituição Federal e ao art. 60 do Ato das Disposições Constitucionais Transitórias. Diário Oficial da União, Brasília, DF, 20 dez. 2006. 
BRASIL. Lei no 9.424, de 24 de dezembro de 1996. Dispõe sobre o Fundo de Manutenção e Desenvolvimento do Ensino Fundamental e de Valorização do Magistério, na forma prevista no art. $60, \S 7^{\circ}$, do Ato das Disposições Constitucionais Transitórias, e dá outras providências. Diário Oficial da União, Brasília, DF, 26 dez. 1996b.

BRASIL. Lei n ${ }^{\circ} 11.414$, de 20 de junho de 2007. Regulamenta o Fundo de Manutenção e Desenvolvimento da Educação Básica e de Valorização dos Profissionais da Educação - FUNDEB, de que trata o art. 60 do Ato das Disposições Constitucionais Transitórias; altera a Lei n o 10.195, de 14 de fevereiro de 2001; revoga dispositivos das Leis $\mathrm{n}$ os 9.424 , de 24 de dezembro de 1996, 10.880, de 9 de junho de 2004, e 10.845, de 5 de março de 2004; e dá outras providências. Diário Oficial da União, Brasília, DF, 21 jun. 2007A.

BRASIL. Lei $\mathrm{n}^{\circ} 13.005$, de 25 de junho de 2014. Aprova o Plano Nacional de Educação - PNE e dá outras providências. Diário Oficial da União, Brasília, DF, 26 jun. 2014.

BRASIL. Política Nacional de Educação Especial na Perspectiva da Educação Inclusiva. Brasília, DF, 2008.

BRASIL. Conselho Nacional de Educação. Câmara de Educação Básica. Resolução CNE/CEB n ${ }^{\circ}$ 2, de 11 de setembro de 2001. Diretrizes Nacionais para a Educação Especial na Educação Básica. Diário Oficial da União, Brasílai, DF, 14 set. 2001.

BRASIL. Senado Federal. Constituição da República Federativa do Brasil. Brasília, DF, 1988.

CAMARGO, R. B.; BASSI, M. E. Gestão democrática na escola pública: participação e controle social no âmbito de um sistema de ensino. In: CORREA, B. C.; GARCIA, T. O. (orgs.). Politicas educacionais e organização do trabalho na escola. São Paulo: Xamã, 2008. p. 97-128.

CARR, W.; KEMMIS, S. Teoría crítica de la enseñanza:

la investigación-acción en la formación del profesorado. Barcelona: Martinez Roca, 1988.

CICHELERO, S. M. T.; LUNARDI, E. M. O plano de ações articuladas e suas influências na gestão da educação municipal: um estado do conhecimento. Jornal de Políticas Educacionais, Curitiba, v. 13, n. 15, p. 1-17, maio 2019. https://doi.com/10.0.21.4/jpe.v13i0.64117 
ESPÍRITO SANTO. Secretaria de Estado da Educação. Portaria $n^{\circ} 92-R$, de 21 de maio de 2014. Estabelece o credenciamento de instituições comunitárias, confessionais ou filantrópicas sem fins lucrativos para o Atendimento Educacional Especializado, no contraturno do ensino regular, aos alunos com deficiência, transtorno global do desenvolvimento, altas habilidades/superdotação. Vitória: SEE, 2014.

FERREIRA, J. R. Financiamento da educação básica: o público e o privado na educação especial brasileira. In: FÁVERO, O. et al. Tornar a educação inclusiva. Brasília: Unesco, 2009. p. 55-64.

FLACH, S. F. A gestão democrática nos sistemas municipais de ensino do Paraná: uma análise a partir dos conselhos municipais de educação. Ensaio: Avaliação e Políticas Públicas em Educação, Rio de Janeiro, v. 28, n.106, p. 221-240, jan./mar. 2020. https://doi.org/10.1590/S0104-40362019002701338

FRANÇA, M. G. Financiamento da Educação Especial: complexas tramas, permanentes contradições e novos desafios. Tese (Doutorado em Educação) - Programa de Pós-Graduação em Educação, Universidade Estadual de São Paulo, São Paulo, 2014.

FRANÇA, M. G.; PRIETO, R. G. Financiamento da educação especial no município de Vitória: desafios à gestão. Educar em Revista, Curitiba, v. 34, n. 71, p. 279-296, set./out. 2018. https://doi.org/10.1590/0104-4060.59229

GOMES, C. A.; AMARAL SOBRINHO, J. Educação Especial no Brasil: perfil do financiamento e das despesas. Brasília, DF: MEC/SEEP/Unesco, 1996.

GONZALEZ, R. K.; PRIETO, R. G. Financiamento da educação especial em município paulista: algumas aproximações com o tema. In: CONGRESSO BRASILEIRO DE EDUCAÇÃO ESPECIAL, 5.; ENCONTRO NACIONAL DOS PESQUISADORES DA EDUCAÇÃO ESPECIAL, 7., 2012, São Carlos. Anais [...] São Carlos: UFSCar, 2012. p. 7475-7488.

HABERMAS, J. Consciência moral e agir comunicativo. 2. ed. Rio de Janeiro: Tempo Brasileiro, 2003.

KASSAR, M. C. M.; REBELO, A. S. Abordagens da Educação Especial no Brasil entre final do século XX e início do século XXI. Revista Brasileira de Educação Especial, Bauru, v. 24, n. especial, p. 51-68, out-dez. 2018. https://doi.org/10.1590/S1413-65382418000400005 
KASSAR, M. C. M.; REBELO, A. S.; OLIVEIRA, R. T. C.

Embates e disputas na política nacional de Educação Especial brasileira. Educação e Pesquisa, São Paulo, v. 45, p. 1-19, 2019. https://doi.org/10.1590/S1678-4634201945217170

MAZZOTTA, M. J. S. Educação Especial no Brasil: história e políticas públicas. 6. ed. São Paulo: Cortez, 2011.

MELO, D. C. F. Entre a luta e o direito: políticas públicas de educação para as pessoas com deficiência visual. Campos dos Goytacazes: Brasil Multicultural, 2016.

NOGUEIRA, J. O.; JESUS, D. M.; EFFGEN, A. P. S.

Ações instituídas e praticadas para elaboração do currículo do curso de formação de gestores públicos em Educação Especial. In: JESUS, D. M. (org.). Gestão da educação especial: pesquisa, política e formação. Curitiba: Appris; Secretaria de Estado da Educação/ES, 2012. p. 161-190.

OLIVEIRA, G. M. Financiamento das instituições especializadas na política de educação especial no Estado do ES. Dissertação (Mestrado em Educação) - Programa de Pós-Graduação em Educação, Universidade Federal do Espírito Santo, Vitória, 2016.

OLIVEIRA, R. P. A municipalização do ensino no Brasil. In. OLIVEIRA, D. (org.). Gestão democrática da educação: desafios contemporâneos. Petrópolis: Vozes, 1997. p. 174-198.

PINTO, J. M. R. A política recente de fundos para o financiamento da educação e seus efeitos no pacto federativo. Edcuação \& Sociedade, Campinas, v. 28, n. 100 - Especial, p. 877-897, out. 2007. https://doi.org/10.1590/S0101-73302007000300012

PRIETO, R. G. P.; PAGNEZ, K. S. M. M.; GONZALEZ, R. K. Educação especial e inclusão escolar: tramas de uma política em implantação. Educação \& Realidade, Porto Alegre, v. 39, n. 3, p. 725-743, set. 2014. http://dx.doi.org/10.1590/S2175-62362014000300006

SALVADOR, E. Fundo público e o financiamento das políticas sociais no Brasil. Serviço Social em Revista, Londrina, v. 14, n. 2, p. 4-22, jan./jun. 2012. https://doi.org/10.5433/1679-4842.2012v14n2p4 
VIEGAS, L. T. A reconfiguração da educação especial e os espaços de atendimento educacional especializado: análise da constituição de um centro de atendimento em Cachoeirinha/RS. Tese (Doutorado em Educação) Programa de Pós-Graduação em Educação, Universidade Federal do Rio Grande do Sul, Porto Alegre, 2014.

VIEGAS, L. T.; BASSI, M. E. A educação especial no âmbito da política de fundos no financiamento da educação. Reflexão \& Ação, Santa Cruz do Sul, v. 17, n. 1, p. 57-83, jan. 2009. http://dx.doi.org/10.17058/rea.v17i1.776

VIEIRA, R. Expectativas e frustrações: a inclusão da EJA no Fundeb. In: ENCONTRO DA ASSOCIAÇÃO DE PESQUISA EM FINANCIAMENTO DA EDUCAÇÃO, 2., 2014. Paraná. Anais [...]. Paraná: UFPR, 2014. p. 94-108.

\section{Informações sobre os autores}

Marileide Gonçalves França: Doutora em Educação pela Universidade de São Paulo. Professora da Graduação e do Programa de Pós-Graduação em Ensino, Educação Básica e Formação de Professores, vinculado ao Centro de Ciências Exatas, Naturais e da Saúde da Universidade Federal do Espírito Santo. Contato: marileide.franca@ufes.br

iD https://orcid.org/0000-0003-1690-6088

Douglas Christian Ferrari de Melo: Doutor em Educação pela Universidade Federal do Espírito Santo. Professor adjunto do Centro de Educação, do Programa de Pós-Graduação de Mestrado Profissional em Educação e do Programa de Pós-Graduação em da mesma universidade. Contato: dochris.ferrari@gmail.com

iD http://orcid.org/0000-0003-2761-0477

Mariangela Lima de Almeida: Doutora em Educação pela Universidade Federal do Espírito Santo. Professora Associada do Programa de Pós-Graduação Mestrado Profissional em Educação e do Programa de Pós-Graduação em Educação do Centro de Educação da mesma universidade. Contato: mlameida.ufes@gmail.com

iD https://orcid.org/0000-0002-7092-2583 